\title{
Modulation of Oxidative and Nitrosative Stress Attenuates Microvascular Hyperpermeability in Ovine Model of Pseudomonas Aeruginosa Sepsis
}

\section{Satoshi Fukuda}

The University of Texas Medical Branch at Galveston

Yosuke Niimi

The University of Texas Medical Branch at Galveston

\section{Yasutaka Hirasawa}

The University of Texas Medical Branch at Galveston

\section{Ennert Manyeza}

The University of Texas Medical Branch at Galveston

\section{Garner}

Salzman Group Inc,.

\section{Garry Southan}

Salzman Group Inc,.

\section{Andrew Salzman}

Salzman Group Inc,.

\section{Donald Prough}

The University of Texas Medical Branch at Galveston

Perenlei Enkhbaatar ( $\sim$ peenkhba@utmb.edu )

The University of Texas Medical Branch at Galveston

\section{Research Article}

Keywords: Sepsis, Vascular Hyperpermeability, Oxidative Stress, Nitrosative Stress, Multi-organ Dysfunction

Posted Date: September 17th, 2021

DOI: https://doi.org/10.21203/rs.3.rs-421490/v2

License: (a) (1) This work is licensed under a Creative Commons Attribution 4.0 International License. Read Full License

Version of Record: A version of this preprint was published at Scientific Reports on December 1st, 2021. See the published version at https://doi.org/10.1038/s41598-021-03320-w. 


\section{Abstract}

In sepsis, microvascular hyperpermeability caused by oxidative/nitrosative stress (O\&NS) plays an important role in tissue edema leading to multi-organ dysfunctions and increased mortality. We hypothesized that a novel compound R-107, a modulator of O\&NS, effectively ameliorates the severity of microvascular hyperpermeability and preserves multi-organ function in ovine sepsis model. Sepsis was induced in twentytwo adult female Merino sheep by intravenous infusion of Pseudomonas aeruginosa (PA) ( $\left.1 \times 10^{10} \mathrm{CFUs}\right)$. The animals were allocated into: 1$)$ Control ( $n=13)$ : intramuscular injection (IM) of saline; and 2) Treatment $(n=9)$ : IM of $50 \mathrm{mg} / \mathrm{kg} \mathrm{R}-107$. The treatment was given after the PA injection, and monitored for 24-hour. R107 treatment significantly reduced fluid requirement $(15-24$ hours, $p<0.05)$, net fluid balance $(9-24$ hours, $p<0.05)$, and water content in lung/heart/kidney $(p=0.02 / 0.04 / 0.01)$ compared to control. R-107 treatment significantly decreased lung injury score/modified sheep SOFA score at 24-hour ( $p=0.01 / 0.04)$, significantly lowered arterial lactate $(21-24$ hours, $p<0.05)$, shed syndecan- 1 ( $3-6$ hours, $p<0.05)$, interleukin- $6(6-12$ hours, $p<0.05$ ) levels in plasma, and significantly attenuated lung tissue 3-nitrotyrosine and vascular endothelial growth factor-A expressions $(p=0.03 / 0.002)$ compared to control. There was no adverse effect in $\mathrm{R}-107$ treatment. In conclusion, modulation of $0 \& N S$ by $\mathrm{R}-107$ reduced hyperpermeability markers and improved multi-organ function.

\section{Introduction}

Sepsis is a life-threatening organ dysfunction caused by a dysregulated host response to infection, and the most frequent cause of death in intensive care units (ICUs) due to multiple organ failure [1,2]. The overall rate of hospital mortality of sepsis is reported at 25-35\% [3-5]. Recent work by Luhr et al. reported that mortality rate of septic patients has remained unchanged over the last two decades [6]. Endothelial cell damage and increased microvascular hyperpermeability caused by excessive oxidative/nitrosative stress (O\&NS) produce interstitial tissue and multi-organ edema, leading to multiple organ dysfunctions and increased mortality [7-11].

Various therapies targeting O\&NS (i.e., superoxide anion, hydrogen peroxide, nitric oxide, and peroxynitrite) have been proposed for treatment of sepsis, however none of them has advanced to clinical practice as a standard therapy [12-14]. The exact reasons for these failed translational studies are unknown, however, it may be related to the lack of approaches that consider the complexity and multifactorial mechanism of O\&NS-induced tissue injury, specifically the imbalance of nitric oxide (NO) and superoxide anion $\left(\mathrm{O}_{2}{ }^{-}\right)$and peroxynitrite in the septic condition [15-20]. The imbalance of these free radical species during sepsis impacts the distribution of extracellular water, disrupts epithelial and endothelial tight junctions, impairs endothelial function and vascular smooth muscle tone, chokes off microcirculatory blood flow, triggers pulmonary arterial hypertension, and raises endothelial hyperpermeability [16-20].

Previously, we tested the effects of the novel anti-O\&NS agent R-100, which has triple actions $-\mathrm{O}_{2}{ }^{-}$catalytic degradation, NO donation, and peroxynitrite decomposition catalysis in a clinically-relevant ovine model of pneumonia/sepsis [21]. 


\section{Results}

\section{Changes in Systemic Cardiopulmonary Hemodynamics and Biochemical Variables During and After Intravenous Bacterial Infusion}

During the 60-minute intravenous infusion of PA, body temperature (BT), heart rate (HR), mean arterial pressure (MAP), mean pulmonary artery pressure (mPAP), central venous pressure (CVP), systemic vascular resistance index (SVRI), pulmonary vascular resistance index (PVRI), and respiratory rate (RR) were increased, and cardiac index $(\mathrm{Cl})$ was decreased in all animals with the peak at 20-30 minutes after the start of the PA infusion. These changes returned to the baseline (BL) values by 90 minutes after the start of the bacterial infusion, with the exception of the BT, HR, mPAP, PVRI, and plasma lactate level, which gradually increased until 180 minutes after the initiation of the bacterial infusion. The greatest increases of end-tidal $\mathrm{CO}_{2}\left(\mathrm{EtCO}_{2}\right)$ and $\mathrm{CO}_{2}$ production $\left(\mathrm{VCO}_{2}\right)$ were observed at 30 minutes; these values then started decreasing 180 minutes after the start of the bacterial infusion. There was no significant difference in all variables between the two groups, indicating comparable injury in the two groups (Table 2). 
Table 2

Changes in Systemic Hemodynamics and Biochemical Variable During and After (Baseline - 180 mins) Bacterial Intravenously Administration.

\begin{tabular}{|c|c|c|c|c|c|c|c|c|}
\hline Parameter & $\begin{array}{l}\text { Group } \\
\text { /Time }\end{array}$ & $B L$ & $\begin{array}{l}30 \\
\min \end{array}$ & $\begin{array}{l}60 \\
\min \end{array}$ & $\begin{array}{l}90 \\
\min \end{array}$ & $\begin{array}{l}120 \\
\min \end{array}$ & $\begin{array}{l}150 \\
\min \end{array}$ & $\begin{array}{l}180 \\
\min \end{array}$ \\
\hline \multirow{2}{*}{$\begin{array}{l}\text { Temperature } \\
\left({ }^{\circ} \mathrm{C}\right)\end{array}$} & Control & $\begin{array}{l}39.0 \\
\pm 0.1\end{array}$ & $\begin{array}{l}40.1 \\
\pm 0.1\end{array}$ & $\begin{array}{l}40.2 \\
\pm 0.1\end{array}$ & $\begin{array}{l}40.4 \\
\pm 0.1\end{array}$ & $\begin{array}{l}40.2 \\
\pm 0.1\end{array}$ & $\begin{array}{l}40.5 \\
\pm 0.2\end{array}$ & $\begin{array}{l}40.6 \\
\pm 0.2\end{array}$ \\
\hline & $\mathrm{R}-107$ & $\begin{array}{l}39.1 \\
\pm 0.1\end{array}$ & $\begin{array}{l}40.2 \\
\pm 0.2\end{array}$ & $\begin{array}{l}40.3 \\
\pm 0.2\end{array}$ & $\begin{array}{l}40.1 \\
\pm 0.1\end{array}$ & $\begin{array}{l}39.9 \\
\pm 0.2\end{array}$ & $\begin{array}{l}40.0 \\
\pm 0.2\end{array}$ & $\begin{array}{l}40.2 \\
\pm 0.2\end{array}$ \\
\hline \multirow[t]{2}{*}{ Heart Rate (beats/min) } & Control & $\begin{array}{l}92 \pm \\
3\end{array}$ & $\begin{array}{l}110 \\
\pm 8\end{array}$ & $\begin{array}{l}126 \\
\pm 10\end{array}$ & $\begin{array}{l}163 \\
\pm 6\end{array}$ & $\begin{array}{l}164 \\
\pm 6\end{array}$ & $\begin{array}{l}174 \\
\pm 8\end{array}$ & $\begin{array}{l}161 \\
\pm 6\end{array}$ \\
\hline & $\mathrm{R}-107$ & $\begin{array}{l}97 \pm \\
4\end{array}$ & $\begin{array}{l}116 \\
\pm 9\end{array}$ & $\begin{array}{l}127 \\
\pm 8\end{array}$ & $\begin{array}{l}171 \\
\pm 11\end{array}$ & $\begin{array}{l}174 \\
\pm 13\end{array}$ & $\begin{array}{l}176 \\
\pm 13\end{array}$ & $\begin{array}{l}162 \\
\pm 11\end{array}$ \\
\hline \multirow[t]{2}{*}{ Mean Arterial Pressure (mmHg) } & Control & $\begin{array}{l}99 \pm \\
2\end{array}$ & $\begin{array}{l}116 \\
\pm 5\end{array}$ & $\begin{array}{l}104 \\
\pm 3\end{array}$ & $\begin{array}{l}90 \pm \\
4\end{array}$ & $\begin{array}{l}93 \pm \\
3\end{array}$ & $\begin{array}{l}94 \pm \\
5\end{array}$ & $\begin{array}{l}98 \pm \\
4\end{array}$ \\
\hline & R-107 & $\begin{array}{l}96 \pm \\
2\end{array}$ & $\begin{array}{l}110 \\
\pm 3\end{array}$ & $\begin{array}{l}108 \\
\pm 7\end{array}$ & $\begin{array}{l}89 \pm \\
5\end{array}$ & $\begin{array}{l}90 \pm \\
3\end{array}$ & $\begin{array}{l}93 \pm \\
3\end{array}$ & $\begin{array}{l}96 \pm \\
2\end{array}$ \\
\hline \multirow{2}{*}{$\begin{array}{l}\text { Mean Pulmonary Artery } \\
\text { Pressure } \\
(\mathrm{mmHg})\end{array}$} & Control & $\begin{array}{l}18 \pm \\
1\end{array}$ & $\begin{array}{l}43 \pm \\
2\end{array}$ & $\begin{array}{l}35 \pm \\
1\end{array}$ & $\begin{array}{l}31 \pm \\
2\end{array}$ & $\begin{array}{l}31 \pm \\
2\end{array}$ & $\begin{array}{l}34 \pm \\
2\end{array}$ & $\begin{array}{l}31 \pm \\
1\end{array}$ \\
\hline & $\mathrm{R}-107$ & $\begin{array}{l}17 \pm \\
1\end{array}$ & $\begin{array}{l}43 \pm \\
2\end{array}$ & $\begin{array}{l}34 \pm \\
2\end{array}$ & $\begin{array}{l}27 \pm \\
2\end{array}$ & $\begin{array}{l}27 \pm \\
1\end{array}$ & $\begin{array}{l}29 \pm \\
1\end{array}$ & $\begin{array}{l}29 \pm \\
2\end{array}$ \\
\hline \multirow{2}{*}{$\begin{array}{l}\text { Central Venous Pressure } \\
(\mathrm{mmHg})\end{array}$} & Control & $4 \pm 1$ & $8 \pm 1$ & $6 \pm 1$ & $6 \pm 1$ & $7 \pm 1$ & $7 \pm 1$ & $6 \pm 1$ \\
\hline & R-107 & $4 \pm 1$ & $7 \pm 1$ & $5 \pm 1$ & $5 \pm 1$ & $6 \pm 1$ & $5 \pm 1$ & $5 \pm 1$ \\
\hline \multirow{2}{*}{$\begin{array}{l}\text { Cardiac Index } \\
\left(\mathrm{mL} / \mathrm{min} / \mathrm{m}^{2}\right)\end{array}$} & Control & $\begin{array}{l}6.4 \pm \\
0.3\end{array}$ & $\begin{array}{l}4.1 \pm \\
0.5\end{array}$ & $\begin{array}{l}4.6 \pm \\
0.4\end{array}$ & $\begin{array}{l}6.7 \pm \\
0.4\end{array}$ & $\begin{array}{l}6.9 \pm \\
0.5\end{array}$ & $\begin{array}{l}5.8 \pm \\
0.4\end{array}$ & $\begin{array}{l}5.7 \pm \\
0.5\end{array}$ \\
\hline & $\mathrm{R}-107$ & $\begin{array}{l}6.3 \pm \\
0.4\end{array}$ & $\begin{array}{l}3.7 \pm \\
0.4\end{array}$ & $\begin{array}{l}5.7 \pm \\
0.4\end{array}$ & $\begin{array}{l}7.1 \pm \\
0.4\end{array}$ & $\begin{array}{l}6.5 \pm \\
0.4\end{array}$ & $\begin{array}{l}6.5 \pm \\
0.4\end{array}$ & $\begin{array}{l}5.4 \pm \\
0.4\end{array}$ \\
\hline \multirow[t]{2}{*}{$\begin{array}{l}\text { Systemic Vascular Resistance } \\
\left.\text { Index (dyne-sec } / \mathrm{cm}^{5} / \mathrm{m}^{2}\right)\end{array}$} & Control & $\begin{array}{l}1214 \\
\pm 65\end{array}$ & $\begin{array}{l}2472 \\
\pm \\
2729\end{array}$ & $\begin{array}{l}1901 \\
\pm 199\end{array}$ & $\begin{array}{l}1037 \\
\pm 72\end{array}$ & $\begin{array}{l}1063 \\
\pm 87\end{array}$ & $\begin{array}{l}1256 \\
\pm 100\end{array}$ & $\begin{array}{l}1449 \\
\pm 155\end{array}$ \\
\hline & $\mathrm{R}-107$ & $\begin{array}{l}1212 \\
\pm 85\end{array}$ & $\begin{array}{l}2427 \\
\pm 280\end{array}$ & $\begin{array}{l}1520 \\
\pm 157\end{array}$ & $\begin{array}{l}973 \\
\pm 86\end{array}$ & $\begin{array}{l}1085 \\
\pm 100\end{array}$ & $\begin{array}{l}1131 \\
\pm 102\end{array}$ & $\begin{array}{l}1418 \\
\pm 101\end{array}$ \\
\hline \multirow{2}{*}{$\begin{array}{l}\text { Pulmonary Vascular } \\
\text { Resistance Index (dyne- } \\
\mathrm{sec} / \mathrm{cm}^{5} / \mathrm{m}^{2} \text { ) }\end{array}$} & Control & $\begin{array}{l}111 \\
\pm 10\end{array}$ & $\begin{array}{l}474 \\
\pm 50\end{array}$ & $\begin{array}{l}320 \\
\pm 31\end{array}$ & $\begin{array}{l}194 \\
\pm 24\end{array}$ & $\begin{array}{l}193 \\
\pm 14\end{array}$ & $\begin{array}{l}255 \\
\pm 15\end{array}$ & $\begin{array}{l}253 \\
\pm 24\end{array}$ \\
\hline & $\mathrm{R}-107$ & $\begin{array}{l}98 \pm \\
9\end{array}$ & $\begin{array}{l}525 \\
\pm 66\end{array}$ & $\begin{array}{l}269 \\
\pm 42\end{array}$ & $\begin{array}{l}167 \\
\pm 20\end{array}$ & $\begin{array}{l}166 \\
\pm 16\end{array}$ & $\begin{array}{l}190 \\
\pm 15\end{array}$ & $\begin{array}{l}223 \\
\pm 29\end{array}$ \\
\hline \multirow{2}{*}{$\begin{array}{l}\text { Respiratory Rate } \\
\text { (rate/min) }\end{array}$} & Control & 20 & $\begin{array}{l}25 \pm \\
2\end{array}$ & $\begin{array}{l}25 \pm \\
2\end{array}$ & $\begin{array}{l}23 \pm \\
2\end{array}$ & $\begin{array}{l}23 \pm \\
2\end{array}$ & $\begin{array}{l}23 \pm \\
2\end{array}$ & $\begin{array}{l}23 \pm \\
1\end{array}$ \\
\hline & $\mathrm{R}-107$ & 20 & $\begin{array}{l}24 \pm \\
2\end{array}$ & $\begin{array}{l}22 \pm \\
1\end{array}$ & $\begin{array}{l}23 \pm \\
2\end{array}$ & $\begin{array}{l}22 \pm \\
2\end{array}$ & $\begin{array}{l}22 \pm \\
2\end{array}$ & $\begin{array}{l}22 \pm \\
1\end{array}$ \\
\hline
\end{tabular}




\begin{tabular}{|c|c|c|c|c|c|c|c|c|}
\hline Parameter & $\begin{array}{l}\text { Group } \\
\text { /Time }\end{array}$ & $B L$ & $\begin{array}{l}30 \\
\text { min }\end{array}$ & $\begin{array}{l}60 \\
\mathrm{~min}\end{array}$ & $\begin{array}{l}90 \\
\text { min }\end{array}$ & $\begin{array}{l}120 \\
\min \end{array}$ & $\begin{array}{l}150 \\
\min \end{array}$ & $\begin{array}{l}180 \\
\mathrm{~min}\end{array}$ \\
\hline \multirow{2}{*}{$\begin{array}{l}\text { End-tidal } \mathrm{CO}_{2} \\
(\mathrm{mmHg})\end{array}$} & Control & - & $\begin{array}{l}32.0 \\
\pm 2.9\end{array}$ & $\begin{array}{l}30.1 \\
\pm 2.1\end{array}$ & $\begin{array}{l}30.7 \\
\pm 1.5\end{array}$ & $\begin{array}{l}32.4 \\
\pm 1.1\end{array}$ & $\begin{array}{l}34.4 \\
\pm 2.2\end{array}$ & $\begin{array}{l}33.1 \\
\pm 1.7\end{array}$ \\
\hline & R-107 & - & $\begin{array}{l}36.3 \\
\pm 2.4\end{array}$ & $\begin{array}{l}31.1 \\
\pm 1.6\end{array}$ & $\begin{array}{l}29.5 \\
\pm 1.5\end{array}$ & $\begin{array}{l}30.2 \\
\pm 2.2\end{array}$ & $\begin{array}{l}33.7 \\
\pm 1.9\end{array}$ & $\begin{array}{l}34.6 \\
\pm 2.5\end{array}$ \\
\hline \multirow{2}{*}{$\begin{array}{l}\mathrm{CO}_{2} \text { Production } \\
\left(\mathrm{VCO}_{2}\right)(\mathrm{mL} / \mathrm{min})\end{array}$} & Control & - & $\begin{array}{l}352 \\
\pm 33\end{array}$ & $\begin{array}{l}252 \\
\pm 28\end{array}$ & $\begin{array}{l}264 \\
\pm 34\end{array}$ & $\begin{array}{l}276 \\
\pm 22\end{array}$ & $\begin{array}{l}294 \\
\pm 23\end{array}$ & $\begin{array}{l}290 \\
\pm 21\end{array}$ \\
\hline & R-107 & - & $\begin{array}{l}333 \\
\pm 28\end{array}$ & $\begin{array}{l}249 \\
\pm 15\end{array}$ & $\begin{array}{l}253 \\
\pm 13\end{array}$ & $\begin{array}{l}246 \\
\pm 21\end{array}$ & $\begin{array}{l}284 \\
\pm 22\end{array}$ & $\begin{array}{l}285 \\
\pm 23\end{array}$ \\
\hline \multirow[t]{2}{*}{$\begin{array}{l}\text { Lactate } \\
\text { (mmol/L) }\end{array}$} & Control & $\begin{array}{l}0.51 \\
\pm \\
0.04\end{array}$ & - & $\begin{array}{l}2.65 \\
\pm \\
0.29\end{array}$ & $\begin{array}{l}2.90 \\
\pm \\
0.37\end{array}$ & $\begin{array}{l}3.00 \\
\pm \\
0.40\end{array}$ & - & $\begin{array}{l}3.37 \\
\pm \\
0.52\end{array}$ \\
\hline & R-107 & $\begin{array}{l}0.52 \\
\pm \\
0.05\end{array}$ & - & $\begin{array}{l}2.20 \\
\pm \\
0.49\end{array}$ & $\begin{array}{l}2.89 \\
\pm \\
0.60\end{array}$ & $\begin{array}{l}2.96 \\
\pm \\
0.62\end{array}$ & - & $\begin{array}{l}2.85 \\
\pm \\
0.61\end{array}$ \\
\hline
\end{tabular}

\section{Survival, qSOFA and mSOFA Scores, Plasma Lactate Clearance, and Lung Injury Score}

During the 24-hour study period, in both groups, MAP was decreased and BT, HR, mPAP, and Cl were increased from their BL values, reflecting a state of hyperdynamic sepsis (Table 1). The BT was significantly higher in R-107 treated sheep at 18-21 hours $(p<0.05)$ compared to control. R-107 significantly attenuated the increases in LAP and CVP at $21-24$ hours $(p<0.01)$ compared to control. R-107 treatment also significantly decreased right ventricular stroke work index at 15 hours $(p<0.05)$, and significantly attenuated the decreases in static lung compliance at 21 hours $(p<0.05)$ as compared to control (Table 1$)$. 
Table 1

Cardiovascular Hemodynamics, Pulmonary Mechanics, Hematocrit, Biochemical Variables, and Systemic Neutrophil Counts during Baseline and at 24-hours.

\begin{tabular}{|c|c|c|c|c|c|c|c|c|}
\hline Parameter & $\begin{array}{l}\text { Group } \\
\text { / Time }\end{array}$ & BL & $6 \mathrm{hr}$ & $\begin{array}{l}12 \\
\mathrm{hr}\end{array}$ & $\begin{array}{l}15 \\
\mathrm{hr}\end{array}$ & $\begin{array}{l}18 \\
\mathrm{hr}\end{array}$ & $\begin{array}{l}21 \\
\mathrm{hr}\end{array}$ & $\begin{array}{l}24 \\
\mathrm{hr}\end{array}$ \\
\hline \multirow{2}{*}{$\begin{array}{l}\text { Temperature } \\
\left({ }^{\circ} \mathrm{C}\right)\end{array}$} & Control & $\begin{array}{l}39.0 \\
\pm 0.1\end{array}$ & $\begin{array}{l}40.8 \\
\pm 0.2\end{array}$ & $\begin{array}{l}40.5 \\
\pm 0.2\end{array}$ & $\begin{array}{l}40.3 \\
\pm 0.3\end{array}$ & $\begin{array}{l}40.1 \\
\pm 0.2\end{array}$ & $\begin{array}{l}40.2 \\
\pm 0.3\end{array}$ & $\begin{array}{l}40.2 \\
\pm 0.2\end{array}$ \\
\hline & $\mathrm{R}-107$ & $\begin{array}{l}39.1 \\
\pm 0.1\end{array}$ & $\begin{array}{l}40.3 \\
\pm 0.1\end{array}$ & $\begin{array}{l}40.6 \\
\pm 0.1\end{array}$ & $\begin{array}{l}40.7 \\
\pm 0.2\end{array}$ & $\begin{array}{l}40.8 \\
\pm 0.2 \\
*\end{array}$ & $\begin{array}{l}40.8 \\
\pm 0.2\end{array}$ & $\begin{array}{l}40.8 \\
\pm 0.2\end{array}$ \\
\hline \multirow{2}{*}{$\begin{array}{l}\text { Heart Rate } \\
\text { (beats/min) }\end{array}$} & Control & $\begin{array}{l}92 \pm \\
3\end{array}$ & $\begin{array}{l}151 \\
\pm 8\end{array}$ & $\begin{array}{l}177 \\
\pm 7\end{array}$ & $\begin{array}{l}181 \\
\pm 8\end{array}$ & $\begin{array}{l}172 \\
\pm 5\end{array}$ & $\begin{array}{l}159 \\
\pm 9\end{array}$ & $\begin{array}{l}164 \\
\pm 10\end{array}$ \\
\hline & $\mathrm{R}-107$ & $\begin{array}{l}97 \pm \\
4\end{array}$ & $\begin{array}{l}169 \\
\pm 8\end{array}$ & $\begin{array}{l}181 \\
\pm 9\end{array}$ & $\begin{array}{l}184 \\
\pm 10\end{array}$ & $\begin{array}{l}168 \\
\pm 11\end{array}$ & $\begin{array}{l}174 \\
\pm 7\end{array}$ & $\begin{array}{l}163 \\
\pm 10\end{array}$ \\
\hline \multirow[t]{2}{*}{ Mean Arterial Pressure (mmHg) } & Control & $\begin{array}{l}99 \pm \\
2\end{array}$ & $\begin{array}{l}98 \pm \\
5\end{array}$ & $\begin{array}{l}86 \pm \\
4\end{array}$ & $\begin{array}{l}88 \pm \\
4\end{array}$ & $\begin{array}{l}86 \pm \\
3\end{array}$ & $\begin{array}{l}87 \pm \\
5\end{array}$ & $\begin{array}{l}83 \pm \\
6\end{array}$ \\
\hline & $\mathrm{R}-107$ & $\begin{array}{l}96 \pm \\
2\end{array}$ & $\begin{array}{l}104 \\
\pm 4\end{array}$ & $\begin{array}{l}87 \pm \\
3\end{array}$ & $\begin{array}{l}91 \pm \\
4\end{array}$ & $\begin{array}{l}93 \pm \\
3\end{array}$ & $\begin{array}{l}91 \pm \\
4\end{array}$ & $\begin{array}{l}92 \pm \\
2\end{array}$ \\
\hline \multirow{2}{*}{$\begin{array}{l}\text { Mean Pulmonary Artery Pressure } \\
(\mathrm{mmHg})\end{array}$} & Control & $\begin{array}{l}18 \pm \\
1\end{array}$ & $\begin{array}{l}31 \pm \\
1\end{array}$ & $\begin{array}{l}35 \pm \\
2\end{array}$ & $\begin{array}{l}39 \pm \\
2\end{array}$ & $\begin{array}{l}38 \pm \\
2\end{array}$ & $\begin{array}{l}35 \pm \\
2\end{array}$ & $\begin{array}{l}32 \pm \\
2\end{array}$ \\
\hline & $\mathrm{R}-107$ & $\begin{array}{l}17 \pm \\
1\end{array}$ & $\begin{array}{l}31 \pm \\
2\end{array}$ & $\begin{array}{l}33 \pm \\
2\end{array}$ & $\begin{array}{l}34 \pm \\
2\end{array}$ & $\begin{array}{l}35 \pm \\
2\end{array}$ & $\begin{array}{l}30 \pm \\
2\end{array}$ & $\begin{array}{l}27 \pm \\
2\end{array}$ \\
\hline \multirow{2}{*}{$\begin{array}{l}\text { Left Atrial } \\
\text { Pressure (mmHg) }\end{array}$} & Control & $6 \pm 1$ & $\begin{array}{l}10 \pm \\
1\end{array}$ & $\begin{array}{l}12 \pm \\
1\end{array}$ & $\begin{array}{l}15 \pm \\
1\end{array}$ & $\begin{array}{l}16 \pm \\
1\end{array}$ & $\begin{array}{l}17 \pm \\
1\end{array}$ & $\begin{array}{l}17 \pm \\
1\end{array}$ \\
\hline & $\mathrm{R}-107$ & $6 \pm 1$ & $9 \pm 1$ & $\begin{array}{l}11 \pm \\
1\end{array}$ & $\begin{array}{l}11 \pm \\
1\end{array}$ & $\begin{array}{l}12 \pm \\
1\end{array}$ & $\begin{array}{l}12 \pm \\
1 \text { ** }\end{array}$ & $\begin{array}{l}11 \pm \\
1 \text { ** }\end{array}$ \\
\hline \multirow[t]{2}{*}{ Central Venous Pressure (mmHg) } & Control & $4 \pm 1$ & $8 \pm 1$ & $\begin{array}{l}11 \pm \\
1\end{array}$ & $\begin{array}{l}13 \pm \\
1\end{array}$ & $\begin{array}{l}13 \pm \\
1\end{array}$ & $\begin{array}{l}15 \pm \\
1\end{array}$ & $\begin{array}{l}15 \pm \\
1\end{array}$ \\
\hline & $\mathrm{R}-107$ & $4 \pm 1$ & $8 \pm 1$ & $\begin{array}{l}10 \pm \\
1\end{array}$ & ${ }_{1}^{11 \pm}$ & $\begin{array}{l}10 \pm \\
1\end{array}$ & $\begin{array}{l}10 \pm \\
1 * *\end{array}$ & $\begin{array}{l}10 \pm \\
1 * *\end{array}$ \\
\hline \multirow{2}{*}{$\begin{array}{l}\text { Cardiac Index } \\
\left(\mathrm{mL} / \mathrm{min} / \mathrm{m}^{2}\right)\end{array}$} & Control & $\begin{array}{l}6.4 \pm \\
0.3\end{array}$ & $\begin{array}{l}4.8 \pm \\
0.4\end{array}$ & $\begin{array}{l}8.1 \\
\pm 0.6\end{array}$ & $\begin{array}{l}9.5 \\
\pm 0.6\end{array}$ & $\begin{array}{l}9.7 \\
\pm 0.8\end{array}$ & $\begin{array}{l}8.6 \\
\pm 0.9\end{array}$ & $\begin{array}{l}9.3 \\
\pm 1.1\end{array}$ \\
\hline & $\mathrm{R}-107$ & $\begin{array}{l}6.3 \pm \\
0.4\end{array}$ & $\begin{array}{l}6.2 \pm \\
0.5\end{array}$ & $\begin{array}{l}8.7 \\
\pm 0.5\end{array}$ & $\begin{array}{l}8.2 \\
\pm 0.7\end{array}$ & $\begin{array}{l}8.2 \\
\pm 0.5\end{array}$ & $\begin{array}{l}8.6 \\
\pm 0.7\end{array}$ & $\begin{array}{l}8.2 \\
\pm 0.7\end{array}$ \\
\hline \multirow{2}{*}{$\begin{array}{l}\text { Stroke Volume } \\
\text { Index (mL/m²/beat) }\end{array}$} & Control & $\begin{array}{l}71 \pm \\
5\end{array}$ & $\begin{array}{l}33 \pm \\
4\end{array}$ & $\begin{array}{l}45 \pm \\
3\end{array}$ & $\begin{array}{l}53 \pm \\
3\end{array}$ & $\begin{array}{l}57 \pm \\
5\end{array}$ & $\begin{array}{l}55 \pm \\
5\end{array}$ & $\begin{array}{l}57 \pm \\
6\end{array}$ \\
\hline & $\mathrm{R}-107$ & $\begin{array}{l}66 \pm \\
5\end{array}$ & $\begin{array}{l}37 \pm \\
3\end{array}$ & $\begin{array}{l}49 \pm \\
4\end{array}$ & $\begin{array}{l}46 \pm \\
5\end{array}$ & $\begin{array}{l}50 \pm \\
3\end{array}$ & $\begin{array}{l}49 \pm \\
3\end{array}$ & $\begin{array}{l}51 \pm \\
4\end{array}$ \\
\hline $\begin{array}{l}\text { Left Ventricular Stroke Work Index } \\
\left(\mathrm{gm}-\mathrm{m} / \mathrm{m}^{2} / \text { beat) }\right.\end{array}$ & Control & $\begin{array}{l}86 \pm \\
6\end{array}$ & $\begin{array}{l}38 \pm \\
6\end{array}$ & $\begin{array}{l}44 \pm \\
3\end{array}$ & $\begin{array}{l}50 \pm \\
4\end{array}$ & $\begin{array}{l}54 \pm \\
5\end{array}$ & $\begin{array}{l}52 \pm \\
6\end{array}$ & $\begin{array}{l}54 \pm \\
6\end{array}$ \\
\hline
\end{tabular}




\begin{tabular}{|c|c|c|c|c|c|c|c|c|}
\hline \multirow[t]{2}{*}{ Parameter } & $\begin{array}{l}\text { Group } \\
\text { / Time }\end{array}$ & BL & $6 \mathrm{hr}$ & $\begin{array}{l}12 \\
\mathrm{hr}\end{array}$ & $\begin{array}{l}15 \\
\mathrm{hr}\end{array}$ & $\begin{array}{l}18 \\
\mathrm{hr}\end{array}$ & $\begin{array}{l}21 \\
\mathrm{hr}\end{array}$ & $\begin{array}{l}24 \\
\mathrm{hr}\end{array}$ \\
\hline & $\mathrm{R}-107$ & $\begin{array}{l}78 \pm \\
6\end{array}$ & $\begin{array}{l}44 \pm \\
4\end{array}$ & $\begin{array}{l}48 \pm \\
5\end{array}$ & $\begin{array}{l}48 \pm \\
6\end{array}$ & $\begin{array}{l}52 \pm \\
3\end{array}$ & $\begin{array}{l}52 \pm \\
3\end{array}$ & $\begin{array}{l}54 \pm \\
3\end{array}$ \\
\hline \multirow[t]{2}{*}{$\begin{array}{l}\text { Right Ventricular Stroke Work Index } \\
\left(\mathrm{gm}-\mathrm{m} / \mathrm{m}^{2} / \text { beat }\right)\end{array}$} & Control & $\begin{array}{l}13 \pm \\
1\end{array}$ & $\begin{array}{l}10 \pm \\
1\end{array}$ & $\begin{array}{l}15 \pm \\
1\end{array}$ & $\begin{array}{l}19 \pm \\
2\end{array}$ & $\begin{array}{l}19 \pm \\
2\end{array}$ & $\begin{array}{l}15 \pm \\
2\end{array}$ & $1^{13 \pm}$ \\
\hline & $\mathrm{R}-107$ & $\begin{array}{l}11 \pm \\
1\end{array}$ & $\begin{array}{l}12 \pm \\
1\end{array}$ & $\begin{array}{l}15 \pm \\
1\end{array}$ & $\begin{array}{l}13 \pm \\
1 *\end{array}$ & $\begin{array}{l}17 \pm \\
2\end{array}$ & $\begin{array}{l}14 \pm \\
1\end{array}$ & $\begin{array}{l}11 \pm \\
1\end{array}$ \\
\hline \multirow[t]{2}{*}{$\begin{array}{l}\text { Systemic Vascular Resistance } \\
\text { Index (dyne-sec } / \mathrm{cm}^{5} / \mathrm{m}^{2} \text { ) }\end{array}$} & Control & $\begin{array}{l}1214 \\
\pm 65\end{array}$ & $\begin{array}{l}1710 \\
\pm 262\end{array}$ & $\begin{array}{l}794 \\
\pm 86\end{array}$ & $\begin{array}{l}672 \\
\pm 78\end{array}$ & $\begin{array}{l}631 \\
\pm 48\end{array}$ & $\begin{array}{l}755 \\
\pm \\
125\end{array}$ & $\begin{array}{l}700 \\
\pm \\
113\end{array}$ \\
\hline & $\mathrm{R}-107$ & $\begin{array}{l}1212 \\
\pm 85\end{array}$ & $\begin{array}{l}1303 \\
\pm 129\end{array}$ & $\begin{array}{l}728 \\
\pm 54\end{array}$ & $\begin{array}{l}822 \\
\pm 71\end{array}$ & $\begin{array}{l}834 \\
\pm 65\end{array}$ & $\begin{array}{l}796 \\
\pm 73\end{array}$ & $\begin{array}{l}845 \\
\pm 86\end{array}$ \\
\hline \multirow[t]{2}{*}{$\begin{array}{l}\text { Pulmonary Vascular Resistance } \\
\text { Index (dyne-sec } / \mathrm{cm}^{5} / \mathrm{m}^{2} \text { ) }\end{array}$} & Control & $\begin{array}{l}111 \\
\pm 10\end{array}$ & $\begin{array}{l}273 \\
\pm 30\end{array}$ & $\begin{array}{l}223 \\
\pm 26\end{array}$ & $\begin{array}{l}188 \\
\pm 20\end{array}$ & $\begin{array}{l}181 \\
\pm 32\end{array}$ & $\begin{array}{l}192 \\
\pm 33\end{array}$ & $\begin{array}{l}155 \\
\pm 40\end{array}$ \\
\hline & $\mathrm{R}-107$ & $\begin{array}{l}98 \pm \\
9\end{array}$ & $\begin{array}{l}220 \\
\pm 30\end{array}$ & $\begin{array}{l}176 \\
\pm 30\end{array}$ & $\begin{array}{l}202 \\
\pm 32\end{array}$ & $\begin{array}{l}189 \\
\pm 14\end{array}$ & $\begin{array}{l}160 \\
\pm 12\end{array}$ & $\begin{array}{l}131 \\
\pm 16\end{array}$ \\
\hline \multirow{2}{*}{$\begin{array}{l}\mathrm{PaO}_{2} / \mathrm{FiO}_{2} \text { Ratio } \\
(\mathrm{mmHg})\end{array}$} & Control & $\begin{array}{l}513 \\
\pm 6\end{array}$ & $\begin{array}{l}467 \\
\pm 29\end{array}$ & $\begin{array}{l}402 \\
\pm 33\end{array}$ & $\begin{array}{l}362 \\
\pm 35\end{array}$ & $\begin{array}{l}320 \\
\pm 45\end{array}$ & $\begin{array}{l}274 \\
\pm 45\end{array}$ & $\begin{array}{l}229 \\
\pm 45\end{array}$ \\
\hline & $\mathrm{R}-107$ & $\begin{array}{l}520 \\
\pm 9\end{array}$ & $\begin{array}{l}507 \\
\pm 27\end{array}$ & $\begin{array}{l}433 \\
\pm 50\end{array}$ & $\begin{array}{l}383 \\
\pm 63\end{array}$ & $\begin{array}{l}380 \\
\pm 80\end{array}$ & $\begin{array}{l}363 \\
\pm 84\end{array}$ & $\begin{array}{l}356 \\
\pm 85\end{array}$ \\
\hline \multirow{2}{*}{$\begin{array}{l}\text { Shunt Fraction } \\
\text { (\%) }\end{array}$} & Control & $6 \pm 1$ & $7 \pm 1$ & $\begin{array}{l}15 \pm \\
3\end{array}$ & $\begin{array}{l}22 \pm \\
4\end{array}$ & $\begin{array}{l}27 \pm \\
6\end{array}$ & $\begin{array}{l}31 \pm \\
8\end{array}$ & $\begin{array}{l}32 \pm \\
5\end{array}$ \\
\hline & $\mathrm{R}-107$ & $5 \pm 1$ & $5 \pm 1$ & $\begin{array}{l}15 \pm \\
3\end{array}$ & $\begin{array}{l}20 \pm \\
5\end{array}$ & $\begin{array}{l}20 \pm \\
7\end{array}$ & $\begin{array}{l}19 \pm \\
6\end{array}$ & $\begin{array}{l}22 \pm \\
8\end{array}$ \\
\hline \multirow{2}{*}{$\begin{array}{l}\text { Peak Airway } \\
\text { Pressure }\left(\mathrm{cmH}_{2} \mathrm{O}\right)\end{array}$} & Control & $\begin{array}{l}20 \pm \\
1\end{array}$ & $\begin{array}{l}26 \pm \\
1\end{array}$ & $\begin{array}{l}32 \pm \\
2\end{array}$ & $\begin{array}{l}33 \pm \\
2\end{array}$ & $\begin{array}{l}33 \pm \\
2\end{array}$ & $\begin{array}{l}34 \pm \\
2\end{array}$ & $\begin{array}{l}32 \pm \\
2\end{array}$ \\
\hline & $\mathrm{R}-107$ & $\begin{array}{l}17 \pm \\
1\end{array}$ & $\begin{array}{l}26 \pm \\
2\end{array}$ & $\begin{array}{l}31 \pm \\
3\end{array}$ & $\begin{array}{l}33 \pm \\
3\end{array}$ & $\begin{array}{l}29 \pm \\
3\end{array}$ & $28 \pm$ & $27 \pm$ \\
\hline \multirow[t]{2}{*}{ Plateau Airway Pressure $\left(\mathrm{cmH}_{2} \mathrm{O}\right)$} & Control & $\begin{array}{l}18 \pm \\
1\end{array}$ & $22 \pm$ & $\begin{array}{l}30 \pm \\
2\end{array}$ & $\begin{array}{l}31 \pm \\
2\end{array}$ & $\begin{array}{l}31 \pm \\
2\end{array}$ & $\begin{array}{l}32 \pm \\
2\end{array}$ & $29 \pm$ \\
\hline & $\mathrm{R}-107$ & $\begin{array}{l}16 \pm \\
1\end{array}$ & $\begin{array}{l}23 \pm \\
2\end{array}$ & $\begin{array}{l}28 \pm \\
3\end{array}$ & $\begin{array}{l}29 \pm \\
3\end{array}$ & $\begin{array}{l}27 \pm \\
3\end{array}$ & $\begin{array}{l}25 \pm \\
3\end{array}$ & $\begin{array}{l}25 \pm \\
3\end{array}$ \\
\hline \multirow[t]{2}{*}{$\begin{array}{l}\text { Lung Static Compliance } \\
\left(\mathrm{mL} / \mathrm{cmH}_{2} \mathrm{O}\right)\end{array}$} & Control & $\begin{array}{l}35 \pm \\
2\end{array}$ & $\begin{array}{l}26 \pm \\
1\end{array}$ & $\begin{array}{l}17 \pm \\
2\end{array}$ & $\begin{array}{l}15 \pm \\
2\end{array}$ & $\begin{array}{l}13 \pm \\
2\end{array}$ & $2^{14 \pm}$ & $\begin{array}{l}17 \pm \\
2\end{array}$ \\
\hline & $\mathrm{R}-107$ & $\begin{array}{l}40 \pm \\
3\end{array}$ & $\begin{array}{l}28 \pm \\
3\end{array}$ & $\begin{array}{l}22 \pm \\
4\end{array}$ & $\begin{array}{l}20 \pm \\
4\end{array}$ & $\begin{array}{l}24 \pm \\
5\end{array}$ & $\begin{array}{l}26 \pm \\
4 *\end{array}$ & $24 \pm$ \\
\hline Hematocrit & Control & $\begin{array}{l}26 \pm \\
1\end{array}$ & $\begin{array}{l}36 \pm \\
1\end{array}$ & $\begin{array}{l}29 \pm \\
1\end{array}$ & $\begin{array}{l}27 \pm \\
1\end{array}$ & $\begin{array}{l}26 \pm \\
1\end{array}$ & $\begin{array}{l}25 \pm \\
1\end{array}$ & $\begin{array}{l}26 \pm \\
1\end{array}$ \\
\hline
\end{tabular}




\begin{tabular}{|c|c|c|c|c|c|c|c|c|}
\hline Parameter & $\begin{array}{l}\text { Group } \\
\text { / Time }\end{array}$ & $B L$ & $6 \mathrm{hr}$ & $\begin{array}{l}12 \\
\mathrm{hr}\end{array}$ & $\begin{array}{l}15 \\
\mathrm{hr}\end{array}$ & $\begin{array}{l}18 \\
\mathrm{hr}\end{array}$ & $\begin{array}{l}21 \\
\mathrm{hr}\end{array}$ & $\begin{array}{l}24 \\
\mathrm{hr}\end{array}$ \\
\hline & R-107 & $\begin{array}{l}26 \pm \\
1\end{array}$ & $\begin{array}{l}32 \pm \\
2\end{array}$ & $\begin{array}{l}27 \pm \\
2\end{array}$ & $\begin{array}{l}27 \pm \\
2\end{array}$ & $\begin{array}{l}26 \pm \\
2\end{array}$ & $\begin{array}{l}25 \pm \\
1\end{array}$ & $\begin{array}{l}25 \pm \\
1\end{array}$ \\
\hline \multirow{2}{*}{$\begin{array}{l}\text { Glucose } \\
\text { (mg/dL) }\end{array}$} & Control & $\begin{array}{l}62 \pm \\
2\end{array}$ & $\begin{array}{l}47 \pm \\
2\end{array}$ & $\begin{array}{l}51 \pm \\
10\end{array}$ & $\begin{array}{l}46 \pm \\
4\end{array}$ & $\begin{array}{l}47 \pm \\
4\end{array}$ & $\begin{array}{l}46 \pm \\
4\end{array}$ & $\begin{array}{l}49 \pm \\
5\end{array}$ \\
\hline & R-107 & $2^{69 \pm}$ & $\begin{array}{l}47 \pm \\
4\end{array}$ & $\begin{array}{l}48 \pm \\
5\end{array}$ & $\begin{array}{l}47 \pm \\
2\end{array}$ & $\begin{array}{l}46 \pm \\
2\end{array}$ & $\begin{array}{l}44 \pm \\
1\end{array}$ & $\begin{array}{l}45 \pm \\
2\end{array}$ \\
\hline \multirow{2}{*}{$\begin{array}{l}\text { Neutrophil } \\
\left(\times 10^{3} \text { cell } / \mu \mathrm{L}\right)\end{array}$} & Control & $\begin{array}{l}2.0 \pm \\
0.2\end{array}$ & $\begin{array}{l}0.6 \pm \\
0.1\end{array}$ & $\begin{array}{l}2.1 \\
\pm 0.4\end{array}$ & - & $\begin{array}{l}3.6 \\
\pm 0.7\end{array}$ & - & $\begin{array}{l}3.2 \\
\pm 1.5\end{array}$ \\
\hline & R-107 & $\begin{array}{l}2.3 \pm \\
0.3\end{array}$ & $\begin{array}{l}1.4 \pm \\
0.7\end{array}$ & $\begin{array}{l}4.0 \\
\pm 1.2\end{array}$ & - & $\begin{array}{l}5.4 \\
\pm 1.7\end{array}$ & - & $\begin{array}{l}5.7 \\
\pm 2.0\end{array}$ \\
\hline
\end{tabular}

The 24-hour survival rate was $89 \%$ (8 out of 9 sheep) for the R-107 treatment group, and $69 \%$ (9 out of 13 sheep) for control (no statistical significance).

R-107 treatment significantly delayed the onset of sepsis compared to control, which was confirmed by the time that sheep met quick SOFA (qSOFA) criteria. Six of 9 sheep in the R-107 group met the qSOFA score criteria within $6.8 \pm 2.0$ hours, whereas all 13 sheep in the control group met these criteria within $3.3 \pm 0.7$ hours from the start of the PA infusion $(p=0.04)($ Fig. 1A).

R-107 treatment significantly attenuated the increases in the modified sheep SOFA (mSOFA) score at 24hours in the survived animals $(n=8$ in the $R-107$ treatment group and $n=9$ in control, $2.9 \pm 1.0$ vs. $5.9 \pm 1.0, p$ $=0.04$ ) as compared to control (Fig. 1B). The measured variables of mSOFA score in both groups are shown in Table 3. 
Table 3

Lung Injury Score and mSOFA Score Variables at 24-hours.

\begin{tabular}{|c|c|c|c|c|c|c|c|}
\hline $\begin{array}{l}\text { Variable } \\
\text { / Group }\end{array}$ & $\begin{array}{l}\text { Respiration } \\
\mathrm{PaO}_{2} / \mathrm{FiO}_{2} \\
(\mathrm{mmHg}) \\
/ \\
\text { mSOFA } \\
\text { Score }\end{array}$ & $\begin{array}{l}\text { Coagulation } \\
\text { Platelets } \\
\left(\times 10^{3} / \mu \mathrm{L}\right) \\
/ \\
\text { mSOFA } \\
\text { Score }\end{array}$ & $\begin{array}{l}\text { Liver } \\
\begin{array}{l}\text { Bilirubin } \\
(\mathrm{mg} / \mathrm{dL})\end{array} \\
/ \\
\text { mSOFA } \\
\text { Score }\end{array}$ & $\begin{array}{l}\text { Cardiovascular } \\
\text { MAP } \\
\text { Decrement } \\
\text { from BL } \\
(\mathrm{mmHg}) \\
/ \\
\text { mSOFA } \\
\text { Score }\end{array}$ & $\begin{array}{l}\text { Central } \\
\text { Nervous } \\
\text { System } \\
\text { SSNAA } \\
(2-11) \\
\text { / } \\
\text { mSOFA } \\
\text { Score }\end{array}$ & $\begin{array}{l}\text { Renal } \\
\text { Creatinine } \\
(\mathrm{mg} / \mathrm{dL}) \\
/ \\
\text { mSOFA } \\
\text { Score }\end{array}$ & $\begin{array}{l}\text { Total } \\
\text { mSOFA } \\
\text { Score } \\
\text { (at 24- } \\
\text { hours) }\end{array}$ \\
\hline Control & $\begin{array}{l}229 \pm 44 \\
/ \\
2.1 \pm 0.5\end{array}$ & $\begin{array}{l}274 \pm 39 \\
/ \\
(0)\end{array}$ & $\begin{array}{l}0.5 \pm 0.1 \\
/ \\
(0)\end{array}$ & $\begin{array}{l}11.3 \pm 5.2 \\
/ \\
1.2 \pm 0.4\end{array}$ & $\begin{array}{l}6.2 \pm \\
0.9 \\
/ \\
2.2 \pm \\
0.4\end{array}$ & $\begin{array}{l}1.0 \pm 0.2 \\
/ \\
0.3 \pm 0.2\end{array}$ & $\begin{array}{l}5.9 \pm \\
1.0\end{array}$ \\
\hline R-107 & $\begin{array}{l}356 \pm 85 \\
/ \\
1.6 \pm 0.7\end{array}$ & $\begin{array}{l}341 \pm 72 \\
/ \\
0.4 \pm 0.4\end{array}$ & $\begin{array}{l}0.2 \pm 0.1 \\
/ \\
(0)\end{array}$ & $\begin{array}{l}4.5 \pm 2.6 \\
/ \\
0.3 \pm 0.2\end{array}$ & $\begin{array}{l}9.6 \pm \\
0.7 \\
/ \\
0.6 \pm \\
0.3\end{array}$ & $\begin{array}{l}0.7 \pm 0.1 \\
/ \\
(0)\end{array}$ & $\begin{array}{l}2.9 \pm \\
1.0 *\end{array}$ \\
\hline
\end{tabular}

Data are expressed as mean \pm SEM. Mann-Whitney U test was performed in the Total mSOFA Score, * $p<$ 0.05 .

Also, the lung injury score (LIS) at 24-hours in the survived animals was significantly lower in the R-107 treatment group as compared to control $(n=8$ in the R-107 treatment group and $n=9$ in control, $1.5 \pm 0.2$ vs. $2.2 \pm 0.2, p=0.01$ ) (Fig. 1C).

R-107 treatment significantly attenuated the increase in plasma lactate levels at $21-24$ hours $(p<0.01)$ (Fig. 1D), and significantly improved lactate clearance during sepsis compared to control at 21-24 hours ( $p$ $<0.05)$ (Fig. 1E).

Fluid Balance, Hematocrit Changes, Plasma Protein Concentration, and Total Amount of Pleural and Ascitic Fluid at Necropsy

The fluid requirement was significantly lower in the R-107 treated group at 15-24 hours $(p<0.05)($ Fig. 2A), and cumulative urine output at 15-24 hours $(p<0.05)$ (Fig. 2B) was significantly higher in the R-107 treated group compared to control. The net fluid balance was significantly attenuated in the R-107 treated group as compared to control at $9-24$ hours $(p<0.05)$ (Fig. $2 C)$. The hematocrit changes during the study period in both groups were comparable (Table 1). 
The plasma protein concentration was significantly higher in the R-107 treated group compared to control at $21-24$ hours $(p<0.05)$ (Fig. 2D).

The combined volume of pleural and ascitic fluid at euthanasia was significantly lower in the R-107 treated group as compared to control ( $21.1 \pm 6.2$ vs. $57.7 \pm 4.7 \mathrm{~mL} / \mathrm{kg} \mathrm{BW}, \mathrm{p}<0.001)$ (Fig. $2 E$ ).

\section{Organ Extravascular Water Content And Bacterial Clearance}

The organ extravascular water content was determined by measuring organ wet-to-dry weight ratio (W/D) at euthanasia. The R-107 treated group displayed significantly lower water content in the lung, heart, and kidney compared to control (lung: $7.5 \pm 0.3$ vs. $8.5 \pm 0.4$, heart: $4.1 \pm 0.1$ vs. $4.4 \pm 0.1$, and kidney: $4.1 \pm 0.02$ vs. $4.2 \pm 0.04, p=0.02,0.04$, and 0.01 , respectively) (Fig. $3 A-3 C$ ).

The number of bacteria in lung and kidney tissue homogenate cultures was significantly lower in the R-107 treated group compared to control $\left(0.4 \pm 0.1\right.$ vs. $1.3 \pm 0.3$ and $0.4 \pm 0.3$ vs. $1.1 \pm 0.3 \times 10^{3} \mathrm{CFUs} / \mathrm{gram}$ tissue in control, $p=0.02$ and 0.02 , respectively) (Fig. 3D, 3E).

\section{Oxidative And Nitrosative Stress, Glycocalyx, And Inflammatory Mediators}

The modulation of O\&NS by the R-107 treatment was measured by the levels of 3-nitrotyrosine in the lung tissue. The 3-nitrotyrosine levels in lung tissue homogenate collected at the euthanasia was significantly lower in the R-107 treated group compared to control ( $0.07 \pm 0.01$ vs. $0.13 \pm 0.02, p=0.02)$ (Fig. $4 A$ ).

R-107 significantly decreased plasma levels of shed syndecan- 1 (Sdc1) at 3 and 6 hours ( $37.0 \pm 6.6$ vs. 88.9 \pm 13.4 and $26.7 \pm 7.7$ vs. $68.8 \pm 10.9, p=0.005$ and 0.03 , at 3 and 6 hours, respectively) compared to control (Fig. 4B).

The plasma interleukin- 6 (IL-6) concentration was significantly lower in the R-107 treated group at 6 and 12 hours ( $2178 \pm 467$ vs. $8732 \pm 918$ and $3817 \pm 1115$ vs. $7585 \pm 1287, p<0.001$ and 0.03 , respectively) compared to control (Fig. 4C). The lung tissue vascular endothelial growth factor-A (VEGF-A) levels were significantly lower in the R-107 treated group compared to control $(0.89 \pm 0.11$ vs. $1.59 \pm 0.12, p<0.001)$ (Fig. 4D).

\section{Discussion}

In this study, we demonstrated that modulation of 0\&NS by R-107 significantly reduced microvascular hyperpermeability and body fluid retention, resulting in improved multi-organ function and survival in septic sheep. Previously, we demonstrated that the modulation of 0\&NS by R-100 significantly reduces systemic fluid retention and improves pulmonary gas exchange in the model of ovine pneumonia/sepsis [21]. The present study results were in an agreement with previous work in terms of reduced fluid retention, organ edema, and microvascular hyperpermeability. In the present study, we further showed that R-107 treatment 
improved bacterial clearance in the lung and kidney, inhibited increases in inflammatory mediators (plasma shed Sdc1, IL-6, and lung VEGF-A levels), delayed the onset of sepsis (measured by the qSOFA score), attenuated multi-organ dysfunction (measured by the mSOFA score), and improved multi-organ function.

In ICU patients with sepsis and septic shock, positive fluid balance, at least in part, due to this microvascular hyperpermeability is not only the independent predictor of mortality, but it also is linked to the increased ICUdays, ventilator-days, and total hospital care costs [35-39]. Therefore, therapies targeting microvascular hyperpermeability and edema formation during sepsis are of particular interest.

As mentioned, sepsis increases microvascular hyperpermeability and excessive fluid retention and causes multiple organ dysfunction by excessive O\&NS [7-9, 40,41]. Excessive O\&NS causes endothelial cell damage and endothelial glycocalyx layer disruption [40-43]. The endothelial glycocalyx layer controls endothelial permeability to water and serves as a barrier to neutrophil/bacteria migration into organ interstitial space from the bloodstream $[7-9,41,42,44,45]$. The Sdc1 is one of the major components of the glycocalyx, and the levels of shed Sdc1 in plasma are considered as a marker of glycocalyx layer disruption during sepsis [45]. Moreover, the plasma shed Sdc1 levels correlate with the increments of plasma IL-6 level during sepsis $[46,47]$.

In addition, VEGF-A, a well-known inflammatory mediator and potent vascular hyperpermeability factor, is increased in septic conditions $[32,34,48]$. In our previous studies, we have shown increases in lung tissue VEGF and myeloperoxidase activity associated with sever microvascular hyperpermeability [34].

The results of the present study demonstrated that R-107 treatment significantly reduced the degree of O\&NS as evidenced by increases in lung tissue 3-nitrotyrosine levels. We also showed that R-107 significantly reduced the plasma levels of shed Sdc1 and IL-6 and significantly attenuated VEGF-A levels in lung tissue compared to control. Although, these findings do not represent causation, we speculate that R-107 attenuated microvascular permeability in this model by inhibiting the potent permeability factor VEGF and preserving endothelial glycocalyx through modulation of O\&NS stress.

In the present study, we reported that the number of bacteria in lung and kidney tissue were significantly lower in the R-107 treatment group compared to control. The underlying mechanisms for this finding are not fully understood. Lubkin et al. reported that PA secretes toxins that disrupt the endothelial cell monolayer barrier mechanism via the induction of oxidative stress $[49,50]$. We speculate that protection of the endothelial barrier by R-107 may be attributed to the reduced number of bacteria in organ tissues. Of note, circulating numbers of neutrophils were not affected by R-107, indicating that differences in bacterial numbers between the two groups were not related to variations in the number of neutrophils.

Further, increases in plasma shed Sdc1 in control were unlikely to have been impacted by the volume of resuscitation fluid because the hematocrit, plasma protein concentration, and hemodynamic variables were comparable in both groups at 3-6 hours, when the plasma shed Sdc1 levels were significantly lower in the R107 treated group compared to control. 
Our present study has several limitations. First, we did not show causative factors by which R-107 reduced microvascular hyperpermeability, rather we showed co-association of the numbers of potent inflammatory mediators with increased vascular permeability. Second, we did not use the supportive therapies, such as antibiotics and vasopressors, which are the standard therapies for sepsis. However, we aimed to explore a "pure" effects of testing compound without any drug interactions. Finally, the study period was relatively short (24-hour), which does not consider the concomitant diseases or factors that are associated with human sepsis. However, the model allowed us to most closely mimic the human hyperdynamic sepsis, continuously monitoring cardiopulmonary hemodynamics in a conscious state without the effects of anesthetics.

In conclusion, modulating excessive O\&NS stress by R-107 may be considered as an effective and safe therapeutic option for management of sepsis-induced microvascular hyperpermeability. Future studies are warranted to further investigate the mechanisms of how moderation of O\&NS by this potential therapeutic compound "R-107" attenuates the pathophysiology of sepsis-induced microvascular hyperpermeability.

\section{Methods}

\section{Animal Model and Experimental Design}

The study was approved by the Institutional Animal Care and Use Committee (IACUC) of the University of Texas Medical Branch and conducted in compliance with the guidelines of the Animal Research: Reporting of In Vivo Experiments [22], the National Institutes of Health, and the American Physiological Society for the care and use of laboratory animals, as previously described [23, 24].

Twenty-two adult female Merino sheep (body weight [BW] $36.8 \pm 1.0 \mathrm{~kg}$ ) were used. Briefly, animals were anesthetized with an intravenous injection of ketamine and isoflurane inhalation, and multiple vascular catheters were surgically inserted (Swan-Ganz, femoral arterial, and left atrial catheters). Pre- and postsurgical analgesia was provided with long-acting (for 72 hours) Buprenorphine SR ${ }^{\mathrm{TM}}(0.05 \mathrm{mg} / \mathrm{kg}, \mathrm{SR}$ Veterinary Technologies, Windsor, CO). Merino sheep were chosen because of their close resemblance of the pathophysiologic and immune responses to infection that are seen in humans [25-27].

After 5-7 days following instrumentation, BL cardiopulmonary hemodynamic variables were collected (Table 1 ), as previously described $[23,24]$. After the BL data were collected, a tracheostomy tube and urine catheter were inserted under ketamine and inhaled isoflurane anesthesia, and animals were placed on a mechanical ventilator (AVEA; Carefusion, Yorba Linda, CA) with the initial settings of a pressure-regulated volume control assist-control mode, tidal volume (TV) of $12 \mathrm{~mL} / \mathrm{kg}$, positive end-expiratory pressure of 5 $\mathrm{cmH}_{2} \mathrm{O}$, RR of 20 breaths/minute, and inspired oxygen concentration $\left(\mathrm{FiO}_{2}\right)$ of 0.21 . Then, $1.0 \times 10^{10} \mathrm{CFUs}$ of Pseudomonas aeruginosa (strain; PD-05144 [12-4-4, BRK-1244, NCIB-10780, NRRL-B-3224], catalog \#: ATCC $\AA 27317^{\mathrm{Tm}}$, ATCC, Manassas, VA) suspended in $50 \mathrm{~mL}$ of warm $0.9 \%$ sodium chloride were intravenously injected (IV) via the jugular vein over 60 minutes in a conscious state. The variables of systemic hemodynamics were continuously monitored during and until 180 minutes after the initiation of the bacterial IV infusion. (Table 2). Arterial lactate levels were also determined during this time period. 


\section{Animal Grouping, Drug Treatment, And Post-injury Care}

After the injury, animals were randomly allocated into two groups: 1) control: treated with an intramuscular injection (IM) of saline, $n=13$; and 2) R-107: administered with IM $50 \mathrm{mg} / \mathrm{kg} R-107, \mathrm{n}=9$. The R-107 was injected into the animal's right quadriceps immediately after completing the infusion of bacteria.

Briefly, R-107 has a multi-functional prodrug technology to target redox imbalance of O\&NS. R-107 is a prodrug ester that hydrolyzes to form R-100 [21], a molecule serving as: a NO donor via its organic nitrate, and a broad-spectrum catalyst of O\&NS degradation via its nitroxide moiety (hydroxymethylproxyl). The spectrum of O\&NS degradation of R-100 includes: $\mathrm{O}_{2}{ }^{-}$dismutation, catalase-like activity (detoxifying $\mathrm{H}_{2} \mathrm{O}_{2}$ ), and peroxynitrite decomposition. There are at present no approved agents with this multi-functional action. R-107 was provided from the Salzman Group Inc. (Beverly, MA).

Cardiopulmonary hemodynamic variables were continuously monitored (IntelliVue MP50; Philips Medical Systems, Andover, MA) (Table 1), and recorded hourly for a 24-hour study period in mechanically-ventilated conscious sheep. RR and $\mathrm{FiO}_{2}$ were adjusted to maintain $\mathrm{PaCO}_{2}$ between $30-40 \mathrm{mmHg}$ and $\mathrm{PaO}_{2} \sim 100$ $\mathrm{mmHg}$, respectively. Arterial and venous blood gas (i.e., arterial and venous $\mathrm{PO}_{2}, \mathrm{PCO}_{2}$, saturation, lactate, hematocrit) were determined using a blood gas analyzer (RAPIDPoint 500; Siemens Healthcare, Erlangen, Germany). Lactate clearance [28] was calculated using the following formula: lactate clearance $=$ (lactate

3 -hours value - lactate delayed time-point value) / lactate 3 -hours value $\times 100$ (expressed as percentage). Plasma protein concentration was measured using a handheld refractometer (National Instrument Company Inc., Baltimore, MD).

Animals were fluid resuscitated with lactated Ringer's solution (LR; Baxter Healthcare Corporation, Deerfield, IL), starting with an initial infusion rate of $2 \mathrm{~mL} / \mathrm{kg} / \mathrm{hr}$ for 3 hours. Thereafter, the LR rate was adjusted every 3 hours to maintain hematocrit close to the BL levels $\pm 3 \%$. Fluid input and urine output were monitored hourly and cumulative fluid balance was calculated, as previously described $[23,24]$.

\section{Quick Sofa And Modified Sheep Sofa Score}

In order to assess the onset of sepsis and the severity of multi-organ dysfunction during sepsis, we used qSOFA and mSOFA scores, as previously described [1, 24, 29]. We measured the time to meet the qSOFA criteria from the initiation of the PA injury. Also, the mSOFA score included the values of animal neurological status, MAP, $\mathrm{PaO}_{2} / \mathrm{FiO}_{2}$ ratio, total platelet counts measured by ADVIA-120 (Siemens Healthcare Diagnostics, Deerfield, IL), and plasma total bilirubin and creatinine concentrations measured by the hospital clinical chemistry laboratory. The neurological status of animal was assessed by the Simplified Sheep Neurological/Alertness Assessment score [29]. The qSOFA score was measured hourly until the animals met the criteria, and the mSOFA score was measured at BL and at the 24-hour timepoint. 


\section{Euthanasia, Tissue Collection, And Tissue Extravascular Water Content Analysis}

After completion of the 24-hour study period, animals were euthanized with injection of ketamine (40 $\mathrm{mg} / \mathrm{kg})$, buprenorphine $(0.01 \mathrm{mg} / \mathrm{kg})$, and xylazine $(3.0 \mathrm{mg} / \mathrm{kg})$, following the IACUC approved protocol and American Veterinary Medical Association Guidelines for Euthanasia [30]. Immediately after euthanasia, organs and tissues were collected, and lung, heart, and kidney tissue water content were measured by W/D, as previously described $[23,24,31]$.

\section{Bacterial Clearance In Lung And Kidney}

To assess bacterial clearance in the lung and kidney, a 1.0-gram section of the dorsal edge of right lung middle lobe and the kidney cortex were taken at necropsy and homogenized in $2 \mathrm{~mL}$ of $1 \mathrm{x}$ phosphatebuffered saline. Then, $200 \mu \mathrm{L}$ of the tissue homogenates were transferred onto soy agar plates. The plates were incubated for 24 hours at $37^{\circ} \mathrm{C}$ for bacterial CFUs counts, as previously described [29].

\section{Western Blotting And Enzyme-linked Immunosorbent Assay}

Western Blotting and Enzyme-linked Immunosorbent Assay

Levels of lung tissue 3-nitrotyrosine [24] and VEGF-A, which is a major mediator of microvascular hyperpermeability [32-34], were determined by automated capillary Western blot analysis $\left(\right.$ Wes $^{\mathrm{TM}}$; ProteinSimple, San Jose, CA), as previously described [24].

The plasma Sdc1 and IL-6 levels were measured by enzyme-linked immunosorbent assay (ELISA) kits following the instructions (Sdc-1; Cat \#: MBS745791, MyBiosource Inc., San Diego, CA, IL-6; Cat \#: SEA0790v, Cloud-Clone Corp., Katy, TX), and as previously described [29].

\section{Statistical Analysis}

All statistical analysis was performed using GraphPad Prism version 8.3.1 (GraphPad Software, Inc., La Jolla, CA). Results were compared between the groups at each timepoint by a two-way analysis of variance with a mixed-effects model with post hoc Bonferroni multiple comparison tests. The values measured at a single timepoint were compared by unpaired t-test or Mann-Whitney $U$ test, based on the normality of the data distribution (Shapiro-Wilk test). All values are expressed as Mean \pm standard error of mean (Mean \pm SEM). Statistical significance was considered for $p$ value $<0.05$.

\section{Abbreviations}

ICU; intensive care unit, O\&NS; oxidative/nitrosative stress, NO; nitric oxide, O2-; superoxide anion, IACUC; institutional animal care and use committee, TV; tidal volume, RR; respiratory rate, FiO2; inspired oxygen concentration, PA; Pseudomonas aeruginosa, IV; intravenous injection, IM; intramuscular injection, BW; body 
weight, LR; lactated Ringer's solution, qSOFA; quick Sequential Organ Failure Assessment, mSOFA; modified sheep Sequential Organ Failure Assessment, MAP; mean arterial pressure, W/D; wet-to-dry weight ratio, VEGF-A; vascular endothelial growth factor-A, Sdc-1; Syndecan-1, IL-6; interleukin-6, ELISA; enzyme-linked immunosorbent assay, BT; body temperature, HR; heart rate, mPAP; mean pulmonary artery pressure, CVP; central venous pressure, SVRI; systemic vascular resistance index, PVRl; pulmonary vascular resistance index, $\mathrm{Cl}$; cardiac index, EtCO2; end-tidal $\mathrm{CO} 2, \mathrm{VCO} 2$; $\mathrm{CO} 2$ production, LIS; lung injury score.

\section{Declarations}

\section{Acknowredgements}

We want to thank the translational intensive care unit personnel for their professionalism and excellent work done to complete this study.

\section{Author contributions statement}

S.F. and P.E. conceived the experiment. S.F., Y.N., Y.H., and E.M. conducted the experiment and analyzed the data. E.G., G.S., A.S., D.P., and P.E. contributed to the final version of the manuscript. All authors reviewed and involved in writing the manuscript.

\section{Funding}

This work was supported by the National Institute of General Medical Sciences [award number NIH GM097480-06A1], and the R-107 was provided by the Salzman Group Inc.

\section{References}

1. Singer M, Deutschman CS, Seymour CW, et al. The Third International Consensus Definitions for Sepsis and Septic Shock (Sepsis-3). 2016;23:315(8):801-10.

2. Fleischmann C, Scherag A, Adhikari NK, Hartog CS, Tsaganos T, Schlattmann P, Angus DC, Reinhart K, International Forum of Acute Care Trialists. Assessment of Global Incidence and Mortality of Hospitaltreated Sepsis. Current Estimates and Limitations. Am J Respir Crit Care Med. 2016;193(3):259-72.

3. Cohen J, Vincent JL, Adhikari NK, et al. Sepsis: a roadmap for future research. Lancet Infect Dis. 2015;15(5):581-614.

4. Rhee C, Dantes R, Epstein L, et al. Incidence and Trends of Sepsis in US Hospitals Using Clinical vs Claims Data, 2009-2014. 2017;318(13):1241-49.

5. Rhee C, Jones TM, Hamad Y, et al. Prevalence, Underlying Causes, and Preventability of SepsisAssociated Mortality in US Acute Care Hospitals. JAMA Netw Open. 2019;2(2):e187571.

6. Luhr R, Cao Y, Söderquist B, Cajander S. Trends in sepsis mortality over time in randomised sepsis trials: a systematic literature review and meta-analysis of mortality in the control arm, 2002-2016. Crit Care. 2019;3;23(1):241. 
7. Huet O, Dupic L, Harrois A, Duranteau J. Oxidative stress and endothelial dysfunction during sepsis. Front Biosci (Landmark Ed). 2011;1;16:1986-95.

8. Coletta C, Módis K, Oláh G, Brunyánszki A, Herzig DS, Sherwood ER, Ungvári Z, Szabo C. Endothelial dysfunction is a potential contributor to multiple organ failure and mortality in aged mice subjected to septic shock: preclinical studies in a murine model of cecal ligation and puncture. Crit Care. 2014;16;18(5):511.

9. Lee WL, Liles WC. Endothelial activation, dysfunction and permeability during severe infections. Curr Opin Hematol. 2011;18(3):191-6.

10. Prauchner CA. Oxidative stress in sepsis: Pathophysiological implications justifying antioxidant cotherapy. 2017;43(3):471-85.

11. Pascual-Ramirez J, Koutrouvelis A. The nitric oxide pathway antagonists in septic shock: Meta-analysis of controlled clinical trials. J Crit Care. 2019;51:34-8.

12. López A, Lorente JA, Steingrub J, et al. Multiple-center, randomized, placebo-controlled, double-blind study of the nitric oxide synthase inhibitor 546C88: effect on survival in patients with septic shock. Crit Care Med. 2004;32(1):21-30.

13. Chelkeba L, Ahmadi A, Abdollahi M, Najafi A, Ghadimi MH, Mosaed R, Mojtahedzadeh M. The effect of parenteral selenium on outcomes of mechanically ventilated patients following sepsis: a prospective randomized clinical trial. Ann Intensive Care. 2015;5(1):29.

14. Fujii T, Luethi N, Young PJ, et al. Effect of Vitamin C, Hydrocortisone, and Thiamine vs Hydrocortisone Alone on Time Alive and Free of Vasopressor Support Among Patients With Septic Shock: The VITAMINS Randomized Clinical Trial. 2020;17;323(5):423-431.

15. Marshall JC. Why have clinical trials in sepsis failed? Trends Mol Med. 2014;20(4):195-203

16. Cui X, Besch V, Khaibullina A, Hergen A, Quezado M, Eichacker P, Quezado ZM. Neuronal nitric oxide synthase deficiency decreases survival in bacterial peritonitis and sepsis. Intensive Care Med. 2007;33(11):1993-2003.

17. Saia RS, Anselmo-Franci JA, Carnio EC. Hypothermia during endotoxemic shock in female mice lacking inducible nitric oxide synthase. 2008;29(1):119-26.

18. Tirosh O, Artan A, Aharoni-Simon M, Ramadori G, Madar Z. Impaired liver glucose production in a murine model of steatosis and endotoxemia: protection by inducible nitric oxide synthase. Antioxid Redox Signal. 2010;1;13(1):13-26.

19. Wang W, Mitra A, Poole B, Falk S, Lucia MS, Tayal S, Schrier R. Endothelial nitric oxide synthase-deficient mice exhibit increased susceptibility to endotoxin-induced acute renal failure. Am J Physiol Renal Physiol. 2004;287(5):F1044-8.

20. Soriano FG, Lorigados CB, Pacher P, Szabo C. Effects of a potent peroxynitrite decomposition catalyst in murine models of endotoxemia and sepsis. 2011;35(6):560-6.

21. Ito H, Malgerud E, Asmussen S, Lopez E, Salzman AL, Enkhbaatar P. R-100 improves pulmonary function and systemic fluid balance in sheep with combined smoke-inhalation injury and Pseudomonas aeruginosa sepsis. J Trans/ Med. 2017;28;15(1):266. 
22. Kilkenny C, Browne WJ, Cuthill IC, Emerson M, Altman DG. Improving bioscience research reporting: the ARRIVE guidelines for reporting animal research. PLoS Biol. 2010;29;8(6):e1000412.

23. Maybauer MO, Maybauer DM, Enkhbaatar P, et al. The selective vasopressin type 1a receptor agonist selepressin (FE 202158) blocks vascular leak in ovine severe sepsis. Crit Care Med. 2014;42(7):e525-33.

24. Fukuda S, Ihara K, Andersen CR, et al. Modulation of Peroxynitrite Reduces Norepinephrine Requirements in Ovine MRSA Septic Shock. 2019;52(5):e92-e99.

25. Nemzek JA, Hugunin KM, Opp MR. Modeling sepsis in the laboratory: merging sound science with animal well-being. Comparative Medicine. 2008;58(2):120-8.

26. Guillon A, Preau S, Aboab J, et al. Preclinical septic shock research: why we need an animal ICU. Ann Intensive Care. 2019;10;9(1):66.

27. Enkhbaatar P, Nelson C, Salsbury JR, Carmical JR, Torres KEO, Herndon D, Prough DS, Luan L, Sherwood ER. Comparison of Gene Expression by Sheep and Human Blood Stimulated with the TLR4 Agonists Lipopolysaccharide and Monophosphoryl Lipid A. PLoS One. 2015;7;10(12):e0144345.

28. Han X, Edelson DP, Snyder A, Pettit N, Sokol S, Barc C, Howell MD, Churpek MM. Implications of Centers for Medicare \& Medicaid Services Severe Sepsis and Septic Shock Early Management Bundle and Initial Lactate Measurement on the Management of Sepsis. Chest. 2018;154(2):302-8.

29. Fukuda S, Ihara K, Bohannon JK, et al. Monophosphoryl lipid A attenuates multiorgan dysfunction during post-burn pseudomonas aeruginosa pneumonia In sheep. 2020;53(3):307-316.

30. Leary S, Underwood W, Anthony R, et al. AVMA Guidelines for the Euthanasia of Animals: 2013 Edition. American Veterinary Medical Association. Schaumburg, Illinois, USA, 2013.

31. Pearce ML, Yamashita J, Beazell J. Measurement of Pulmonary Edema. Circ Res. 1965;16:482-8.

32. Pacher P, Beckman JS, Liaudet L. Nitric oxide and peroxynitrite in health and disease. Physiol Rev. 2007;87(1):315-424.

33. Yano K, Liaw PC, Mullington JM, et al. Vascular endothelial growth factor is an important determinant of sepsis morbidity and mortality. J Exp Med. 2006;12;203(6):1447-58.

34. Lange M, Hamahata A, Enkhbaatar P, et al. Assessment of vascular permeability in an ovine model of acute lung injury and pneumonia-induced Pseudomonas aeruginosa sepsis. Crit Care Med. 2008;36(4):1284-9.

35. Sirvent JM, Ferri C, Baró A, Murcia C, Lorencio C. Fluid balance in sepsis and septic shock as a determining factor of mortality. Am J Emerg Med. 2015;33(2):186-9.

36. Vincent JL, De Backer D, Wiedermann CJ. Fluid management in sepsis: The potential beneficial effects of albumin. J Crit Care. 2016;35:161-7.

37. Sakr Y, Rubatto Birri PN, Kotfis K, Nanchal R, Shah B, Kluge S, Schroeder ME, Marshall JC, Vincent JL, Intensive Care Over Nations Investigators. Higher Fluid Balance Increases the Risk of Death From Sepsis: Results From a Large International Audit. Crit Care Med. 2017;45(3):386-94.

38. Tigabu BM, Davari M, Kebriaeezadeh A, Mojtahedzadeh M. Fluid volume, fluid balance and patient outcome in severe sepsis and septic shock: A systematic review. J Crit Care. 2018;48:153-9. 
39. Silversides JA, Major E, Ferguson AJ, Mann EE, McAuley DF, Marshall JC, Blackwood B, Fan E. Conservative fluid management or deresuscitation for patients with sepsis or acute respiratory distress syndrome following the resuscitation phase of critical illness: a systematic review and meta-analysis. Intensive Care Med. 2017;43(2):155-70.

40. Ince C, Mayeux PR, Nguyen T, Gomez H, Kellum JA, Ospina-Tascón GA, Hernandez G, Murray P, De Backer D, ADQI XIV Workgroup. The Endothelium in Sepsis. 2016;45(3):259-70.

41. Uchimido R, Schmidt EP, Shapiro NI. The glycocalyx: a novel diagnostic and therapeutic target in sepsis. Crit Care. 2019;17;23(1):16.

42. Becker BF, Jacob M, Leipert S, Salmon AHJ, Chappell D. Degradation of the endothelial glycocalyx in clinical settings: searching for the sheddases. Br J Clin Pharmacol. 2015;80(3):389-402.

43. Paulus P, Jennewein C, Zacharowski K. Biomarkers of endothelial dysfunction: can they help us deciphering systemic inflammation and sepsis? 2011;16 Suppl 1:S11-21.

44. Savery MD, Jiang JX, Park PW, Damiano ER. The endothelial glycocalyx in syndecan-1 deficient mice. Microvasc Res. 2013;87:83-91.

45. Martin L, Koczera P, Zechendorf E, Schuerholz T. The Endothelial Glycocalyx: New Diagnostic and Therapeutic Approaches in Sepsis. Biomed Res Int. 2016;2016:3758278.

46. Nelson A, Johansson J, Tydén J, Bodelsson M. Circulating syndecans during critical illness. 2017;125(5):468-75.

47. Steppan J, Hofer S, Funke B, Brenner T, Henrich M, Martin E, Weitz J, Hofmann U, Weigand MA. Sepsis and major abdominal surgery lead to flaking of the endothelial glycocalix. J Surg Res. 2011;165(1):13641.

48. Bermejo-Martin JF, Martín-Fernandez M, López-Mestanza C, Duque P, Almansa R. Shared Features of Endothelial Dysfunction between Sepsis and Its Preceding Risk Factors (Aging and Chronic Disease). $J$ Clin Med. 2018;30;7(11):400.

49. Lubkin A, Torres VJ. Bacteria and endothelial cells: a toxic relationship. Curr Opin Microbiol. 2017;35:5863.

50. Saliba AM, de Assis MC, Nishi R, Raymond B, Marques EA, Lopes UG, Touqui L, Plotkowski MC. Implications of oxidative stress in the cytotoxicity of Pseudomonas aeruginosa ExoU. Microbes Infect. 2006;8(2):450-9.

\section{Figures}




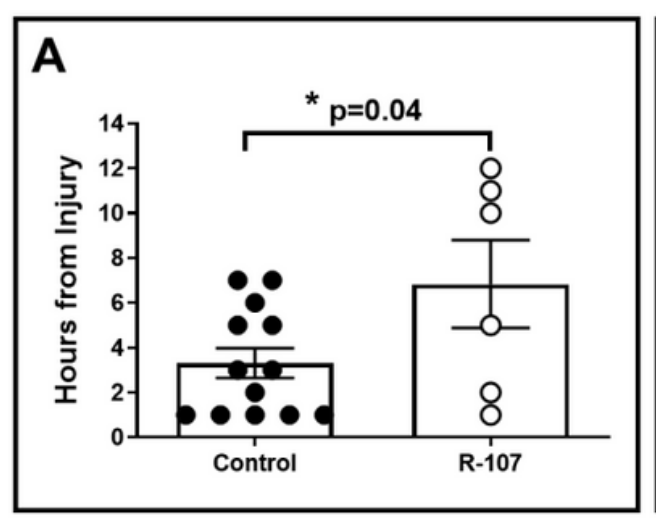

B

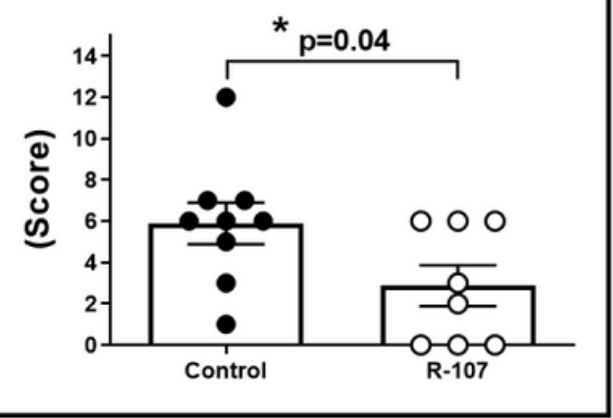

C

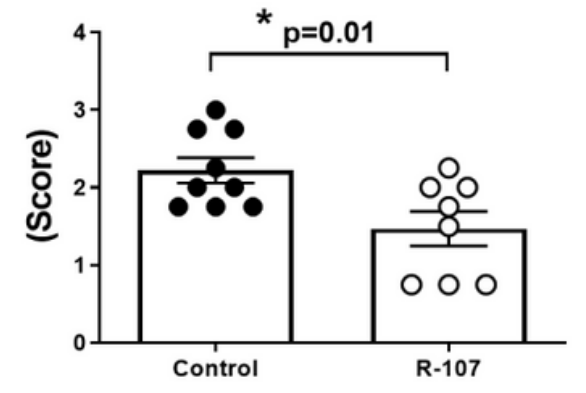

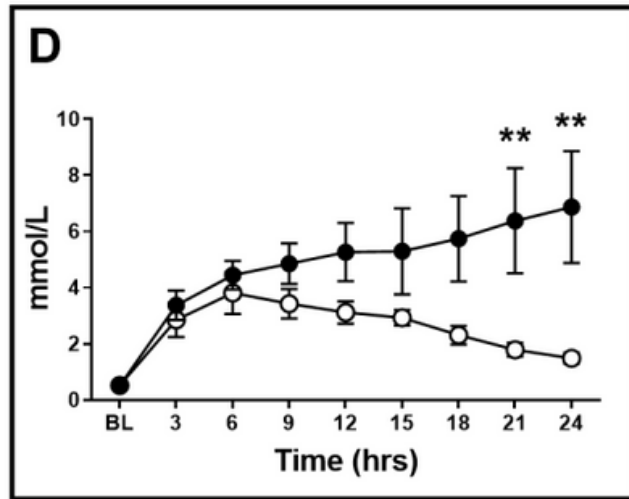

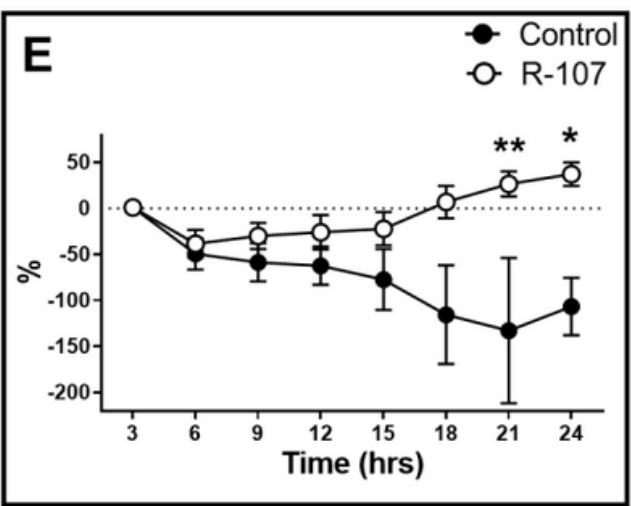

\section{Figure 1}

Quick SOFA and Modified Sheep SOFA Scores, Plasma Lactate Clearance, and Lung Injury Score (A) Time met the quick SOFA criteria from the injection of Pseudomonas aeruginosa in two groups $(n=13$ in control and $n=6$ in the R-107 treatment group). (B) Modified sheep SOFA scores at baseline and at 24-hours in two groups ( $n=9$ in control and $n=8$ in the $R-107$ treatment group at 24-hours). (C) Lung injury score at 24-hours in two groups ( $n=9$ in control and $n=8$ in the $R-107$ treatment group). (D) Plasma lactate concentration during the baseline and at 24-hours in two groups. (E) Lactate clearance from the 3-hours value during the baseline and at 24-hours in two groups. Closed circles represent control group and open circles represent the R-107 treatment group. Data are expressed as mean \pm SEM. $\left({ }^{*} p<0.05\right.$, $* \star p<0.01$, and $* \star \star ~ p<0.001$, Control vs. R-107 treatment group.) 

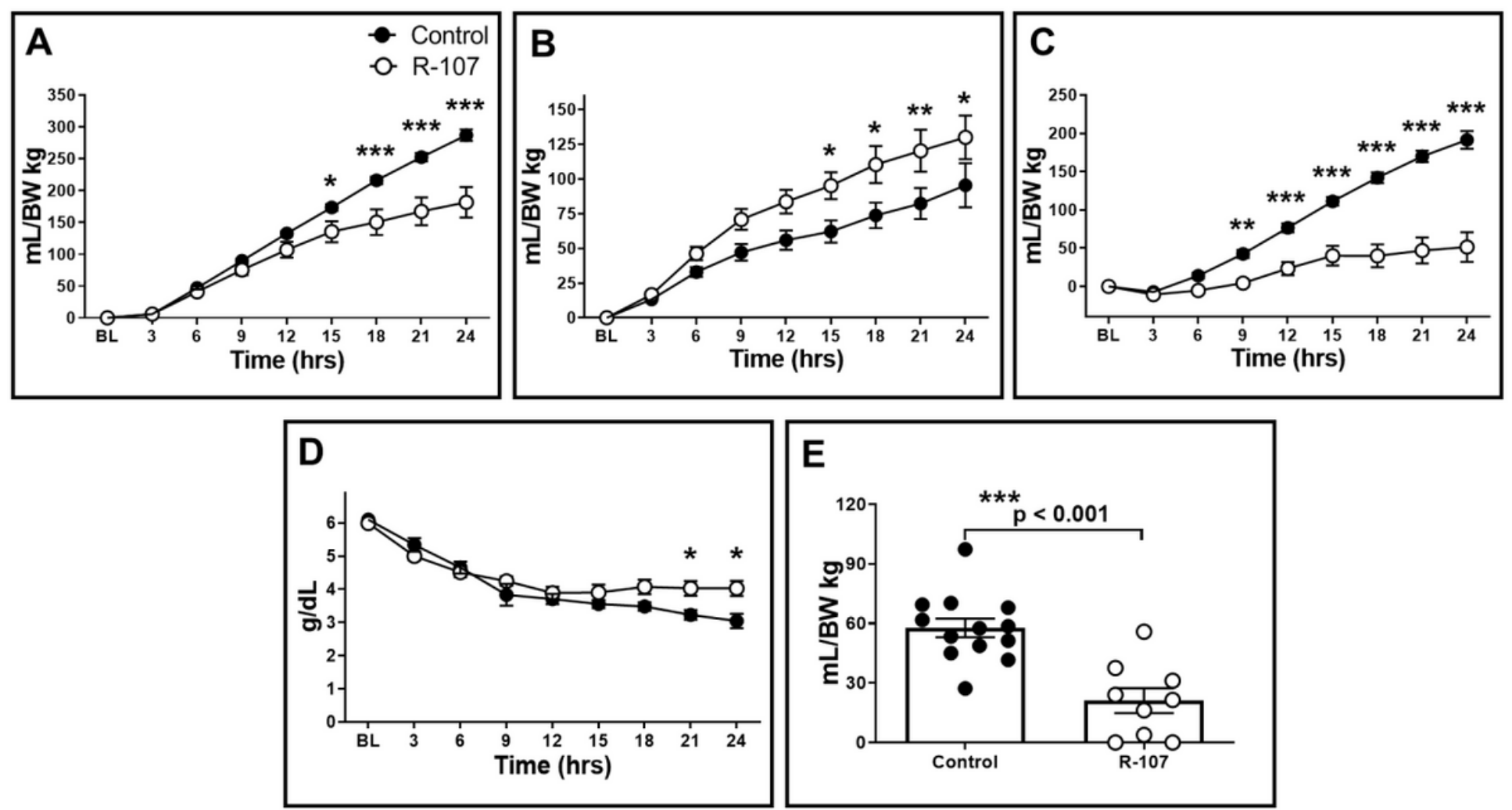

\section{Figure 2}

Fluid Balance, Plasma Protein Concentration, and Total Amount of Pleural and Ascitic Fluid at Necropsy (A) Fluid requirement during the baseline and at 24-hours in two groups. (B) Cumulative urine output during the baseline and at 24-hours in two groups. (C) Net fluid balance during the baseline and at 24-hours in two groups. (D) Plasma protein concentration during the baseline and at 24-hours in two groups. (E) Combined volume of pleural and ascitic fluid measured at euthanasia in two groups. Closed circles represent control group and open circles represent the R-107 treatment group. Data are expressed as mean \pm SEM. ( ${ }^{*}<0.05$, ** $p<0.01$, and $* \star \star p<0.001$, Control vs. $R-107$ treatment group.) 

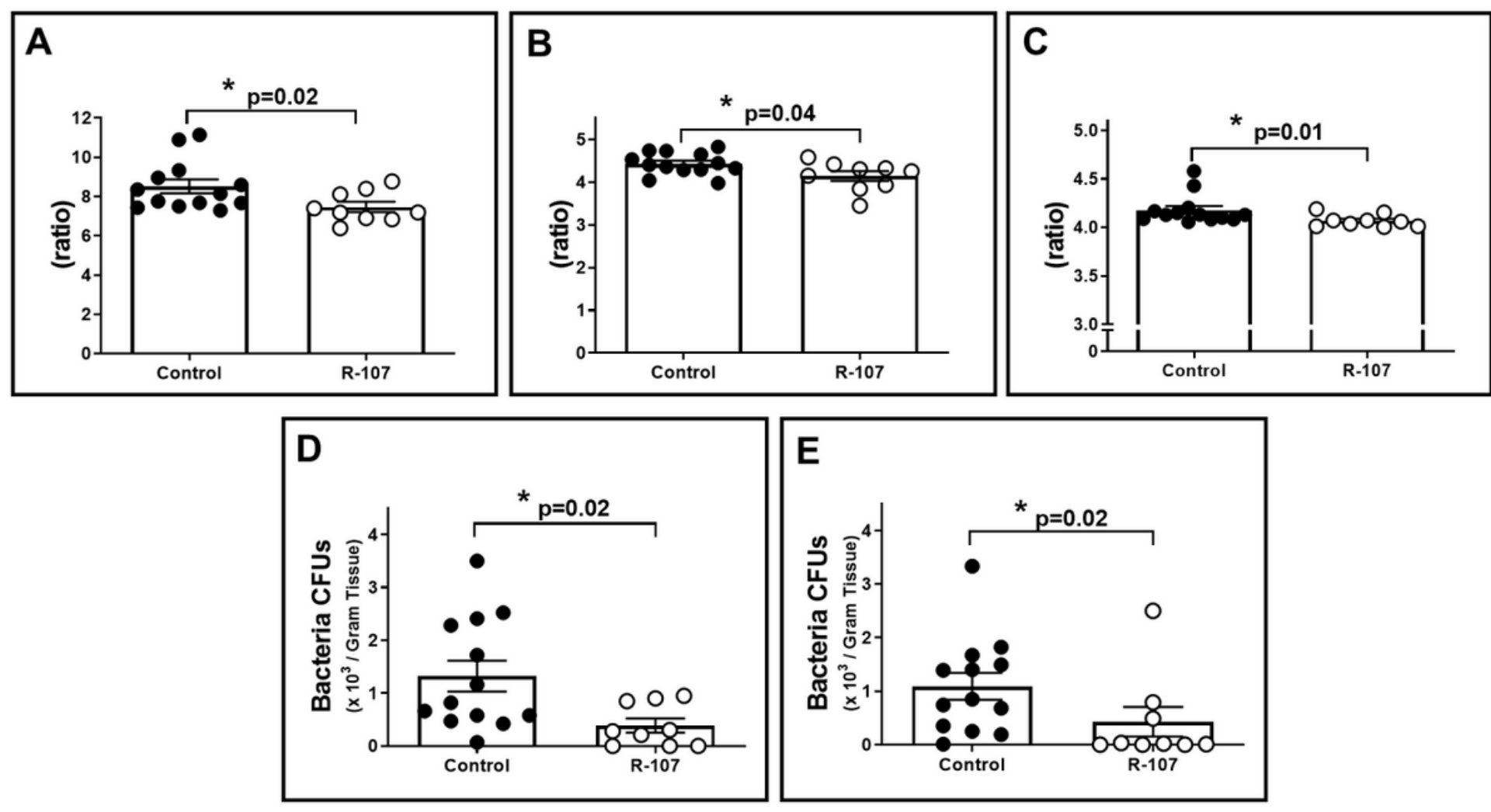

\section{Figure 3}

Organ Extravascular Water Content and Bacterial Clearance (A) Lung extravascular water content at euthanasia in two groups. (B) Heart extravascular water content at euthanasia in two groups. (C) Kidney extravascular water content at euthanasia in two groups. (D) Numbers of bacteria in lung tissue homogenate cultures collected at euthanasia in two groups. (E) Numbers of bacteria in kidney tissue homogenate cultures collected at euthanasia in two groups. Closed circles represent control group and open circles

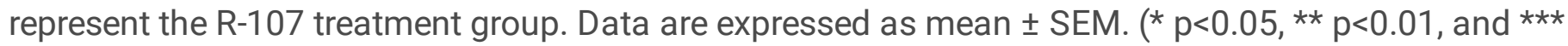
$\mathrm{p}<0.001$, Control vs. $\mathrm{R}-107$ treatment group.) 

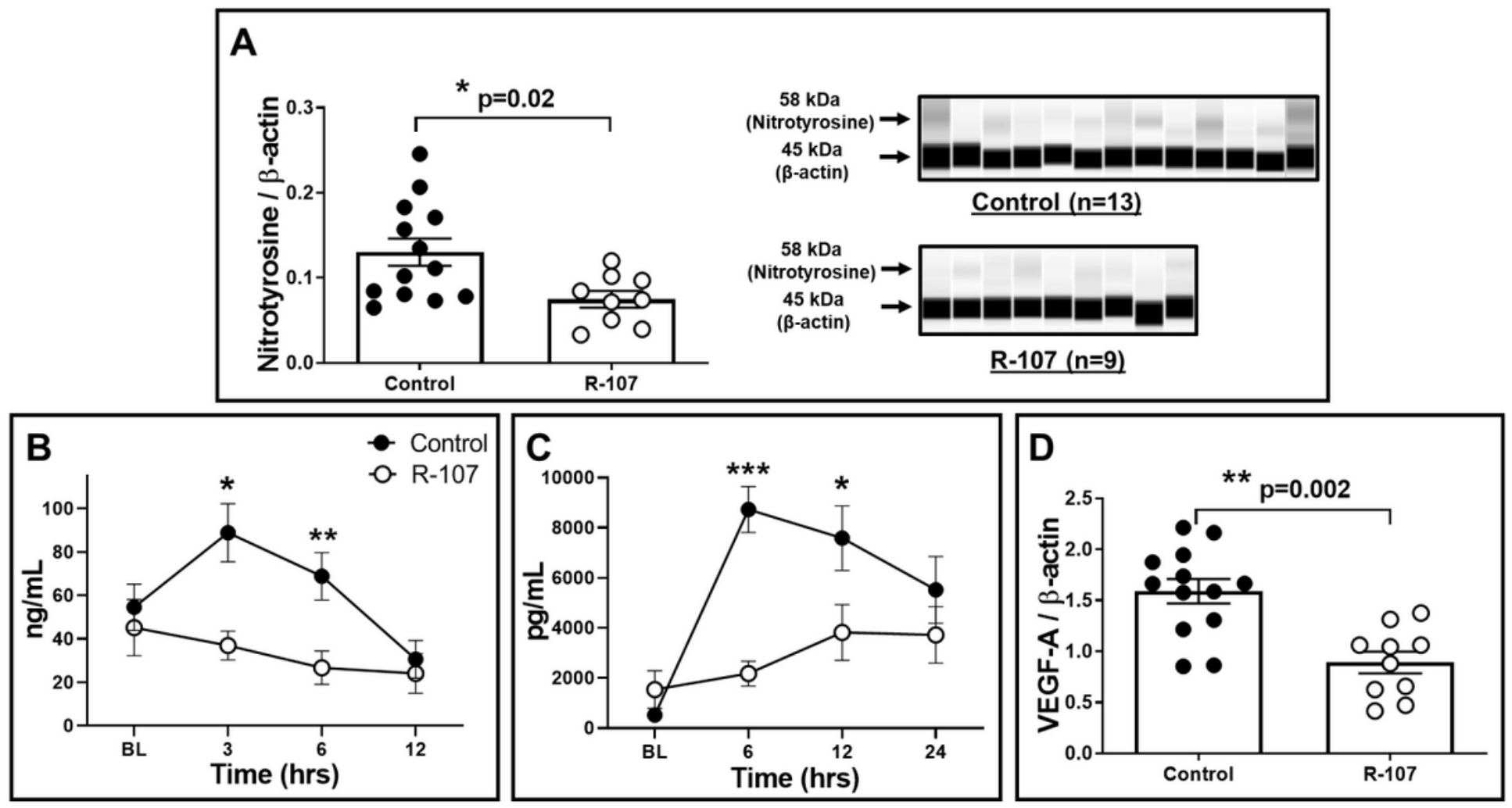

\section{Figure 4}

Oxidative and Nitrosative Stress, Glycocalyx, and Inflammatory Mediators (A) 3-nitrotyrosine level in lung tissue homogenate collected at euthanasia in two groups. (B) Plasma shed syndecan-1 concentration during the baseline and at 12-hours in two groups. (C) Plasma interleukin-6 concentration during the baseline and at 24-hours in two groups. (D) Vascular endothelial growth factor-A level in lung tissue homogenate collected at euthanasia in two groups. Closed circles represent control group and open circles represent the R-107 treatment group. Data are expressed as mean \pm SEM. $\left({ }^{*} p<0.05\right.$, $* * p<0.01$, and ${ }^{* \star *} p<0.001$, Control vs. R-107 treatment group.) 